\title{
Enhancement of Insulin Action after Oral Glucose Ingestion
}

\author{
William J. Kingston, James N. Livingston, and Richard T. Moxley III \\ Departments of Neurology and Medicine, University of Rochester School of Medicine and Dentistry, Rochester, New York 14642
}

\begin{abstract}
Previous investigations in normal humans and rats have shown an increase in insulin sensitivity and binding affinity of adipocytes isolated 1-3 $\mathrm{h}$ after glucose ingestion. To determine whether a rapid enhancement of the action of insulin follows glucose ingestion in vivo, the present studies have utilized 120-min $20 \mathrm{mU} /$ $\mathrm{m}^{2} \cdot \mathrm{min}$ euglycemic insulin infusions before and after 7.5-, 15-, 25-, and 100-g oral glucose loads. Euglycemic insulin infusions after the carbohydrate challenge were begun after arterialized blood glucose and insulin values had returned to baseline. After 15- and 25-g oral glucose loads during the 20-120-min interval of insulin infusion, glucose infusion rates increased by $44 \pm 6 \%$ $(P<0.0001)$ and $47 \pm 9 \%(P<0.0002)$, respectively. No significant differences in arterialized glucose or insulin values existed between basal and post-glucose insulin infusions. In addition, no significant differences in hepatic glucose production or counterregulatory hormone levels were found between basal and postglucose insulin infusions. Control infusion studies including subjects who ingested saline or mannitol failed to show an increase in insulin action. Studies were carried out to mimic the insulin curve seen after 15- and 25-g oral glucose loads. Euglycemic insulin infusions after these insulin simulation studies show a $34 \pm 7 \%$ enhancement compared to baseline euglycemic insulin infusions.

These results demonstrate a rapid enhancement of insulin action after oral glucose challenge in normal humans. The insulin simulation studies suggest that insulin itself either directly or through release of another factor acts on muscle to increase insulin sensitivity. The increase in insulin action demonstrated in these investigations may represent an important regulatory mechanism to modulate tissue insulin sensitivity.
\end{abstract}

\section{Introduction}

Whether glucose loading has the ability to produce an abrupt improvement in the action of insulin on its target tissues is an intriguing question that dates back to early studies by Hamman and Hirschman (1), Staub (2), and Traugott (3). These investigations and more recent studies have demonstrated the development of improved carbohydrate tolerance after a second or additional carbohydrate challenges given 45-60 min after the previous glucose load (4-6). This so-called "Staub-Traugott" effect is not clearly understood, but it may be mediated by facilitation of the action of insulin on peripheral tissues rather than by an increased release of the hormone (6).

Received for publication 27 March 1985 and in revised form 2 December 1985.

J. Clin. Invest.

(c) The American Society for Clinical Investigation, Inc. $0021-9738 / 86 / 04 / 1153 / 10 \quad \$ 1.00$

Volume 77, April 1986, 1153-1162
Many investigations have demonstrated that target tissues for insulin can undergo changes in insulin sensitivity and insulin responsiveness. These changes usually develop in a chronic fashion and result in insulin resistance (7). In contrast to these well-established circumstances that involve long-term regulation of insulin action, relatively little experimental evidence is available describing acute modulation of the insulin response. We (8) and others (9) have reported an increased binding affinity of the insulin receptor in monocytes isolated 2 and $5 \mathrm{~h}$ after glucose ingestion. The physiologic significance of these findings is not clear, but more recent investigations have suggested that oral glucose can produce a rapid enhancement in the action of insulin on target tissues $(10,11)$. A marked increase (200-fold) in insulininduced inhibition of lipolysis and a $20-30 \%$ increase in insulinbinding affinity has been seen in human fat cells taken $1 \mathrm{~h}$ after a 100-g glucose load (10). In animal studies carried out in this laboratory rat adipocytes isolated 2-3 h after glucose feeding have demonstrated a $71-100 \%$ increase in insulin-stimulated lipid synthesis from glucose and have shown an associated mild increase $(20-25 \%)$ in receptor affinity (11).

These recently published observations have provided a major stimulus for the investigations in this report. The present studies were designed to search for evidence of a mechanism that produces a rapid enhancement in the action of insulin after oral glucose ingestion in humans. The euglycemic insulin infusion method (12) was used in these studies because it provides an accurate, reproducible, estimate of insulin action in vivo, particularly the glucose disposal by skeletal muscle $(12,13)$. We hypothesized that if a rapid, physiologically significant, increase in the action of insulin develops after glucose ingestion, the effect should involve this tissue.

The results of the present studies demonstrate that a rapid increase in insulin action occurs in intact humans within $2-3 \mathrm{~h}$ after the ingestion of low doses of glucose (15 and $25 \mathrm{~g}$ ). This enhancement in insulin action may represent an important physiologic regulatory mechanism that may become deranged in certain insulin-resistant states.

\section{Methods}

\section{Subjects}

Fifty-one normal healthy male volunteers participated in these studies. Characteristics of these subjects are listed in Table I. The ages ranged from 19 to $46 \mathrm{yr}$ and the weights ranged from $85 \%$ to $125 \%$ of ideal body weight (based on Metropolitan Life Insurance Tables, 1959). Two of the volunteers were within $125 \%$ of ideal body weight, whereas the remainder of the subjects were within $120 \%$ of ideal body weight. All subjects were on a meat-free diet at home for $2 \mathrm{~d}$ prior to admission to the Clinical Research Center at the University of Rochester. Each subject consumed a weight-maintaining meat-free diet containing $300 \mathrm{~g}$ of carbohydrate and $1.2 \mathrm{~g} / \mathrm{kg}$ of protein per day during his $5-\mathrm{d}$ hospitalization. This diet allowed accurate determination of 24-h urinary creatinine excretion; this was performed on days 1,2 , and 3 before the euglycemic insulin-infusion studies. Volunteers remained ambulatory but did not exercise vigorously during the admission period. Complete blood count with differential white cell count, platelet count, serum sodium, chloride, 


\begin{tabular}{|c|c|c|c|c|c|}
\hline Study group & Age & Height & Weight & $\begin{array}{l}\text { Obesity } \\
\text { index }\end{array}$ & $\begin{array}{l}\text { 24-h urinary creatinine } \\
\text { excretion }\end{array}$ \\
\hline & $y r$ & $\mathrm{~cm}$ & $k g$ & & $m g / 24 h$ \\
\hline $7.5 \mathrm{~g}(n=2)^{*}$ & $28.88 \pm 6.16$ & $173.00 \pm 2.20$ & $82.42 \pm 1.39$ & $1.24 \pm 0.01$ & $1,616.50 \pm 15.17$ \\
\hline $15 \mathrm{~g}(n=16)^{*}$ & $28.13 \pm 1.52$ & $177.14 \pm 1.52$ & $73.12 \pm 2.18$ & $1.08 \pm 0.03$ & $1,626.67 \pm 42.76$ \\
\hline $25 \mathrm{~g}(n=13)^{*}$ & $27.70 \pm 1.73$ & $180.08 \pm 2.02$ & $75.35 \pm 2.46$ & $1.07 \pm 0.03$ & $1,770.54 \pm 74.59$ \\
\hline $100 \mathrm{~g}(n=6)^{*}$ & $27.86 \pm 1.78$ & $181.13 \pm 2.80$ & $78.75 \pm 5.20$ & $1.10 \pm 0.06$ & $1,726.44 \pm 134.01$ \\
\hline 15 g Mannitol $(n=2) \ddagger$ & $28.14 \pm 0.22$ & $183.55 \pm 2.25$ & $88.64 \pm 3.04$ & $1.15 \pm 0.06$ & $1,928.50 \pm 58.50$ \\
\hline 25 g Mannitol $(n=2) \ddagger$ & $28.71 \pm 7.57$ & $178.35 \pm 0.15$ & $75.98 \pm 6.99$ & $1.11 \pm 0.10$ & $1,597.50 \pm 11.5$ \\
\hline $200 \mathrm{ml} \mathrm{NS}(n=2) \S$ & $22.05 \pm 1.16$ & $177.65 \pm 1.65$ & $71.93 \pm 0.58$ & $1.06 \pm 0.04$ & $1,556.50 \pm 102.5$ \\
\hline Waiting period $(n=2)^{\| \prime}$ & $33.77 \pm 12.50$ & $181.35 \pm 3.45$ & $75.35 \pm 3.27$ & $1.06 \pm 0.09$ & $1,906.60 \pm 19.67$ \\
\hline Reproducibility of $\overline{\mathrm{M}}(n=5) \pi$ & $27.59 \pm 2.44$ & $184.56 \pm 2.77$ & $70.06 \pm 4.27$ & $0.94 \pm 0.05$ & $1,618.53 \pm 110.24$ \\
\hline Insulin simulation $(n=9)^{* *}$ & $25.75 \pm 1.68$ & $177.93 \pm 1.30$ & $72.34 \pm 1.79$ & $1.06 \pm 0.02$ & $1,581.0 \pm 68.5$ \\
\hline
\end{tabular}

All values represent the mean \pm SEM. $n$ refers to the number of subjects in each group. ${ }^{*}$ Subjects in these groups received a dose of oral glucose on one of two study days prior to the euglycemic insulin infusion. On the other study day only a euglycemic insulin infusion was performed. ₹ Subjects in these groups received a dose of oral mannitol on one of the two study days prior to the 120 -min euglycemic insulin infusion. On the other study day only a euglycemic insulin infusion was performed. § Subjects in this group received $200 \mathrm{ml}$ of normal saline (same volume used in oral glucose and mannitol studies) on one of the two study days prior to the 120-min euglycemic insulin infusion. On the other study day only a euglycemic insulin infusion was performed. "Subjects in this group received the same euglycemic insulin infusion on the two study days, but one of the two paired studies was delayed by $2 \mathrm{~h}$ to approximate the time interval that occurred in those studies preceded by either oral glucose, mannitol, or saline. I Subjects in this group received identical 120 -min euglycemic insulin infusions at the same times on consecutive days to estimate the reproducibility of the mean glucose disposal rates. ${ }^{* *}$ Subjects in these studies received a variable low dose insulin infusion for 60 min on one study day immediately prior to the 120 -min euglycemic insulin infusion. On the other study day only a euglycemic insulin infusion was performed.

potassium, urea nitrogen, creatinine, carbon dioxide, blood sugar, uric acid, total bilirubin, lactic dehydrogenase, serum aspartate amino-transferase, alkaline phosphatase, total protein, albumin, calcium, inorganic phosphate, cholesterol, as well as urinalysis and chest $\mathrm{x}$-ray were obtained in each subject to search for covert systemic disease. All studies were carried out in the postabsorptive state at 8:00 a.m. after a 12-h overnight fast. The purpose and potential risks of the procedures were explained to all subjects and written voluntary consent was obtained prior to their participation. This study had previously been approved by the Human Investigations Committee at the University of Rochester and by the Clinical Research Center of the University of Rochester.

120-min euglycemic insulin (U-100 Regular Iletin II Purified Pork Insulin Injection, Eli Lilly \& Co., Indianapolis, IN) infusions using a rate of $20 \mathrm{mU} / \mathrm{m}^{2} \cdot \min$ were carried out on days 4 and 5 . A total of 123 euglycemic insulin infusions were performed on the 51 normal volunteers. This infusion rate was chosen to achieve a concentration in the linear portion of the dose-response curve for insulin to allow detection of changes in insulin sensitivity after glucose loading. The study method attempted to evaluate the effect that different doses of oral glucose $(7.5,15,25$, and $100 \mathrm{~g}$ ) had on insulin sensitivity. Each group of subjects was randomized so that half of the group had a "baseline" euglycemic insulin clamp on day 4 , and an oral glucose load before the clamp on day 5 , whereas the other half had the oral glucose load followed by an insulin clamp on day 4 , and the "baseline" clamp on day 5 .

\section{Oral glucose loads}

Glucose and insulin levels were measured in the postabsorptive state and after oral glucose loading. When the glucose had returned to a stable baseline for $\mathbf{3 0} \mathrm{min}$, the euglycemic insulin infusion was begun. In a subset of subjects given the 15- and 25-g oral glucose loads (six subjects) additional blood samples were collected at specific time intervals after the glucose challenge and during the subsequent 120 -min euglycemic insulin infusion for measurement of glucagon, epinephrine, norepinephrine, dopamine, growth hormone, and cortisol.

\section{Control studies}

Specific control studies included the ingestion of mannitol or normal saline in a volume identical to that ingested in the oral glucose studies. Two subjects were given $25 \mathrm{~g}$ of oral mannitol preceding one of their insulin-clamp studies. In an attempt to make these studies comparable to the oral glucose studies, a waiting period of $130.0 \pm 5.0 \mathrm{~min}$ was selected prior to initiating the $20-\mathrm{mU} / \mathrm{m}^{2} \cdot \min 120$-min euglycemic insulin infusion. An additional two subjects had 15-g oral mannitol studies with a waiting period of $125.0 \pm 5.0 \mathrm{~min}$. Two subjects ingested $200 \mathrm{ml}$ of normal saline and had a waiting period of $130.0 \pm 10.0 \mathrm{~min}$. Two subjects received the usual $20-\mathrm{mU} / \mathrm{m}^{2} \cdot \min 120$-min euglycemic insulin infusion on consecutive days (Table II). One of these insulin clamps was preceded by a waiting period of $130 \mathrm{~min}$. Five subjects had $20 \mathrm{mU} / \mathrm{m}^{2} \cdot \mathrm{min}$ euglycemic insulin infusions performed identically on the days 4 and 5 to assess the reproducibility of the procedure (Table I).

\section{Insulin simulation controls}

These studies refer to a group of nine subjects who had euglycemic insulin infusions on days 4 and 5 . One study was preceded by an insulin infusion designed to mimic the changes in the concentration of insulin in arterialized blood seen after the 15-and 25-g oral glucose loads. An incremental and decremental infusion pattern for insulin was chosen based upon pilot studies. The range of insulin infusion rates used to produce this pattern was $5-30 \mathrm{mU} / \mathrm{m}^{2} \cdot \mathrm{min}$. The time required for this insulin release simulation infusion ranged 30-60 min. Glucose was infused during this period to maintain glucose at its baseline preinfusion level. The glucose infusion was gradually reduced over the $30 \mathrm{~min}$ after the insulin infusion, again maintaining glucose at its baseline level. When no further glucose infusion was required to maintain glucose at its stable baseline and the concentration of glucose had remained stable for an additional $30 \mathrm{~min}$, the standard $120-\mathrm{min} 20-\mathrm{mU} / \mathrm{m}^{2} \cdot \min$ euglycemic insulin infusion was begun. The mean time required for completion of the insulin simulation studies before initiating the euglycemic insulin infusions was $103 \pm 11 \mathrm{~min}$ 
Table II. Blood Glucose, Serum Insulin, and Glucose Disposal Rates during

120-min $20 \mathrm{mU} / \mathrm{m}^{2} \cdot$ min Euglycemic Insulin Infusions in Control Studies

\begin{tabular}{|c|c|c|c|c|c|c|c|}
\hline & $\begin{array}{l}\text { Mean* } \\
\text { glucose }\end{array}$ & CV & $\begin{array}{l}\text { Mean } \\
\text { insulinł§ }\end{array}$ & GIR $_{20-120 \S}$ & $\begin{array}{l}\text { Percent increase } \\
\text { of GIR } 20-120 \\
\text { from basal day§ }\end{array}$ & GIR $_{80-120 \$}$ & $\begin{array}{l}\text { Percent increase } \\
\text { of GIR } \text { sa-120 } \\
\text { from basal day§ }\end{array}$ \\
\hline & $m g / d l$ & $\%$ & $\mu U / m l$ & $\mathrm{mg} / \mathrm{kg} \cdot \min$ & $\%$ & $\mathrm{mg} / \mathrm{kg} \cdot \min$ & $\mathscr{H}$ \\
\hline \multicolumn{8}{|l|}{ Without waiting } \\
\hline period $(n=2)$ & 84 & 3 & $39.50 \pm 2.0$ & $4.40 \pm .92$ & & $5.31 \pm 1.08$ & \\
\hline Waiting period & 80 & 3 & $39.08 \pm 0.92$ & $3.96 \pm .33$ & $-8.39 \pm 11.53$ & $4.67 \pm 0.54$ & $-10.48 \pm 1.94$ \\
\hline \multicolumn{8}{|l|}{ Reproducibility } \\
\hline Day $1(n=5)$ & 81 & 4 & $38.80 \pm 1.93$ & $4.50 \pm .30$ & & $5.18 \pm 0.52$ & \\
\hline Day 2 & 81 & 5 & $37.53 \pm 2.09$ & $3.99 \pm .44$ & $-12.18 \pm 5.23$ & $4.87 \pm 0.59$ & $-6.83 \pm 2.80$ \\
\hline
\end{tabular}

CV, coefficient of variation.

* Mean of 24 values during the insulin infusion. $¥$ Mean of six values during the insulin infusion. $\S$ Values represent the mean \pm SEM.

\section{Euglycemic insulin infusion rate}

The technique for the euglycemic insulin infusion has been described in detail previously (12) and outlined below is the summary of procedures followed in the present investigations. A catheter inserted intravenously into the antecubital region of one arm and threaded toward the heart was used for infusion of glucose and insulin. Another intravenous line was inserted retrogradely into a vein in the dorsum of the opposite hand and was used to obtain arterialized blood samples. This hand was placed in a hotbox heated to $70^{\circ} \mathrm{C}(14)$. The euglycemic insulin infusion was carried out by giving a logarithmically declining insulin infusion over the first $10 \mathrm{~min}$ of the study (12). This was followed by $110 \mathrm{~min}$ of constant insulin infusion and the whole blood glucose level was maintained at basal preinsulin levels by a variable glucose infusion using commercially available $20 \%$ dextrose (actual concentration $18.6 \%$ dextrose). Blood glucose was measured at 2-5-min intervals during the study using a Yellow Springs Instruments (Yellow Springs, $\mathrm{OH}$ ) whole blood glucose analyzer. Insulin infusates from the euglycemic insulin infusion studies were diluted and insulin concentrations were measured in the infusates. Similarly, the tritiated glucose infusates were diluted and the amount of tracer measured in each infusate.

\section{Endogenous hepatic glucose production}

Primed continuous tritiated glucose infusions were carried out in four patients to assess hepatic glucose production during the performance of these investigations. These subjects were admitted for a total of $8 \mathrm{~d}$ to the Clinical Research Center. Diet and activity were identical to that described above. During these studies the baseline euglycemic insulin infusion was performed on day 4 whereas the oral glucose clamp study was performed on day 8 .

For $180 \mathrm{~min}$ before starting the baseline insulin infusion, each subject's glucose pool was labeled by a primed continuous infusion of tritiated glucose (15). The tritiated glucose was administered as an initial priming dose, $25 \mu \mathrm{Ci}$, followed immediately by a continuous intravenous infusion at a rate of $0.25 \mu \mathrm{Ci} / \mathrm{min}$. Plasma samples (modified Somogyi-Nelson preparations) were drawn for determination of tracer glucose specific activity at 30-min intervals for the first $2 \mathrm{~h}$ and at 10-15-min intervals for the subsequent hour. Based upon previous investigations with this method a steady-state plateau of glucose specific activity reliably developed in all participants during the third hour of tritiated glucose infusion (15). This plateau value was used to calculate basal hepatic glucose production. After the initial 3-h tritiated glucose infusion the insulin infusion was begun as noted above, and the infusion of tritiated glucose was continued at the same rate. During the euglycemic insulin infusion, plasma samples for glucose specific activity were drawn every $15 \mathrm{~min}$ for the first 90 min, and every 5-10 min thereafter. Basal tracer free plasma was drawn and treated as all other subsequent samples, to establish a background count. Basal plasma was spiked with known amounts of tritiated glucose to confirm recovery efficiency. Hepatic glucose output (16) was calculated using the Steele equations in their modified derivative form.

On day 8 each of the four subjects received either a 15- or 25-g oral glucose load. When the glucose had returned to a stable baseline for 30 min the tritiated glucose infusion was initiated. A $25-\mu \mathrm{Ci}$ priming dose was followed immediately by a continuous intravenous infusion at the rate of $0.25 \mu \mathrm{Ci}$ per min. After $30 \mathrm{~min}$ the euglycemic insulin infusion was begun and the tritiated glucose infusion was continued at the same rate. Blood samples were drawn and evaluated in the same manner as on day 4. No subject received more than $200 \mu \mathrm{Ci}$ during the admission. An additional five normal volunteers received a tritiated glucose infusion for $180 \mathrm{~min}$ before and during ingestion of a $15-\mathrm{g}$ dose of oral glucose and the infusion was continued for an additional $240 \mathrm{~min}$. These investigations were performed to demonstrate that the rate of glucose appearance had returned to baseline level before the initiation of the postglucose euglycemic insulin infusion.

\section{Calculations}

Calculations of glucose disposal rate during the insulin infusion studies. The glucose infusion rate (GIR) ${ }^{1}$ was determined by calculating the mean value observed from 20 to 120 and from 80 to $120 \mathrm{~min}$ (12). To calculate the steady-state plasma glucose and insulin concentrations during the insulin infusion, the mean of the values from 20 to 120 min was employed.

Calculation of hepatic glucose production. The assessment of glucose production in the basal state and during euglycemic insulin infusion has been described in detail previously $(15,17)$. Glucose production in the basal state was determined by dividing the tritiated glucose infusion rate by the steady-state plateau of tritiated glucose specific activity achieved during the last hour of tritiated glucose infusion. The rate of glucose appearance was assumed to be equivalent to the rate of hepatic glucose production, in that renal glucose production is negligible in the overnight fasted state. After initiation of the euglycemic insulin infusion a nonsteady-state condition in glucose specific activity exists and hepatic glucose production was calculated from Steele's equations in their derivative form which permits the evaluation of continuous changes in the rates of glucose turnover (15). The value of 0.65 fraction in these calculations is based on past studies. The validity of this approach for both steady and nonsteady states is supported by recent investigation (18). The rate of endogenous glucose production was calculated by subtracting the glucose infusion rate from the rate of glucose appearance determined from the isotope tracer technique. All computations were performed using a programmable model 67 Hewlitt-Packard Co. (Palo Alto, CA) desk calculator using previously established programs.

\section{Abbreviations used in this paper: GIR, glucose infusion rate.}


All data are presented as the mean \pm standard error of the mean. Statistical comparisons between euglycemic insulin infusion studies before or after oral glucose loads were calculated by $t$ test analysis (19).

\section{Analytical procedures}

Whole blood glucose was determined with the glucose oxidase method using the YSI model 23A glucose analyzer (Scientific Division, Yellow Springs Instrument Company, Inc.). Blood samples for plasma immunoreactive glucagon measurements were collected in chilled tubes containing $1.2 \mathrm{mg}$ of Na EGTA and 500 kallikrein inhibitor units Trasylol per milliliter of blood. Plasma was immediately separated and stored at $-20^{\circ} \mathrm{C}$ until glucagon was assayed using a modification (20) of a previously described radioimmunoassay using Unger antiserum 30K (21). Serum insulin was determined with a modification (22) of a double-antibody technique (23). The specific activity of plasma glucose was determined by a previously described method (15). Blood samples for catecholamine determinations were collected in chilled Vacutainer tubes containing $9 \mathrm{mg}$ of EGTA and $6 \mathrm{mg}$ of glutathione, centrifuged immediately, and stored at $-70^{\circ} \mathrm{C}$ until dopamine, epinephrine, and norepinephrine were measured by a modification (24) of the radioenzymatic technique of Passon and Peuler (25). Reagents for the catecholamine assays were supplied by the Upjohn Laboratories (Kalamazoo, MI). The cortisol assay (Clinical Assays, Cambridge, MA) was sensitive to $1 \mu \mathrm{g} /$ $\mathrm{dl}$, and used standard radioimmunoassay techniques. Growth hormone was determined with a modification of a described double-antibody technique (26).

\section{Results}

Fig. 1 presents the profiles of glucose and insulin levels in arterialized blood in those subjects who received the 25-, 15-, and 7.5-g oral glucose loads. Glucose and insulin mean concentrations reached their peak at $30 \mathrm{~min}$ after the 15- and 7.5-g doses of glucose. At $60 \mathrm{~min}$ mean glucose and insulin concentrations remained elevated in the group receiving the $25-\mathrm{g}$ dose, but had returned toward baseline in subjects with the 15 - and 7.5-g glu- cose loads. The group who received the $25-\mathrm{g}$ dose required a mean \pm SEM of $171 \pm 7$ min for their glucose and insulin levels to return to a stable baseline whereas those who received 15 and $7.5 \mathrm{~g}$ of glucose required $118 \pm 3$ and $107 \pm 2 \mathrm{~min}$, respectively. The elevations in glucose and insulin were similar to those previously reported in subjects given 25 and $12.5 \mathrm{~g}$ of oral glucose $(27,28)$.

$30 \mathrm{~min}$ after blood glucose levels reached a stable post-glucose baseline each group of subjects $(25,15$, and $7.5 \mathrm{~g})$ were given $20 \mathrm{mU} / \mathrm{m}^{2} \cdot \mathrm{min}$ euglycemic insulin infusions, and the results were compared to those obtained on the day in which there was no preceding glucose load. Table III summarizes the results of these studies. Both the 25- and 15-g doses of glucose produced a significant increase in the whole body action of insulin as indicated by the percent increase in GIR compared to basal. This was apparent in both the $\operatorname{GIR}_{20-120}(25 \mathrm{~g}-47 \%, P<0.0002 ; 15$ $\mathrm{g}-44 \%, P<0.0001)$ and in $\operatorname{GIR}_{80-120}(25 \mathrm{~g}-38 \%, P<0.0001$; $15 \mathrm{~g}-41 \%, P<0.0001)$ values. This rapid enhancement in insulin action developed within the first $80 \mathrm{~min}$ of the postglucose insulin infusion. The maximum slope (Fig. 2) of the GIR plotted at 5-min intervals during the initial 10-30 min time intervals were as follows: 25 -g slope during time interval of 10 $30 \mathrm{~min}$ was $0.15 \pm 0.02 \mathrm{vs}$. the basal day slope for this period of $0.09 \pm 0.02, P<0.01$; The slope for the $15-\mathrm{g}$ dose at this time was $0.15 \pm 0.01$ vs. the basal value $0.09 \pm 0.02, P<0.01$.

The clearance of insulin was calculated during the baseline and post-glucose insulin infusions for the groups receiving 15and 25-g oral glucose loads. Insulin clearance was not significantly different between the baseline and post-glucose insulin infusions. Insulin clearances were $737 \pm 33$ and $751 \pm 64 \mathrm{ml} /$ $\mathrm{m}^{2} \cdot \mathrm{min}$ during baseline insulin infusions in the $15-$ and $25-\mathrm{g}$ glucose groups, respectively. Insulin clearances were $739 \pm 32$ and $737 \pm 63 \mathrm{ml} / \mathrm{m}^{2} \cdot \min$ during the insulin infusions after $15-$ and 25-g oral glucose loads, respectively.
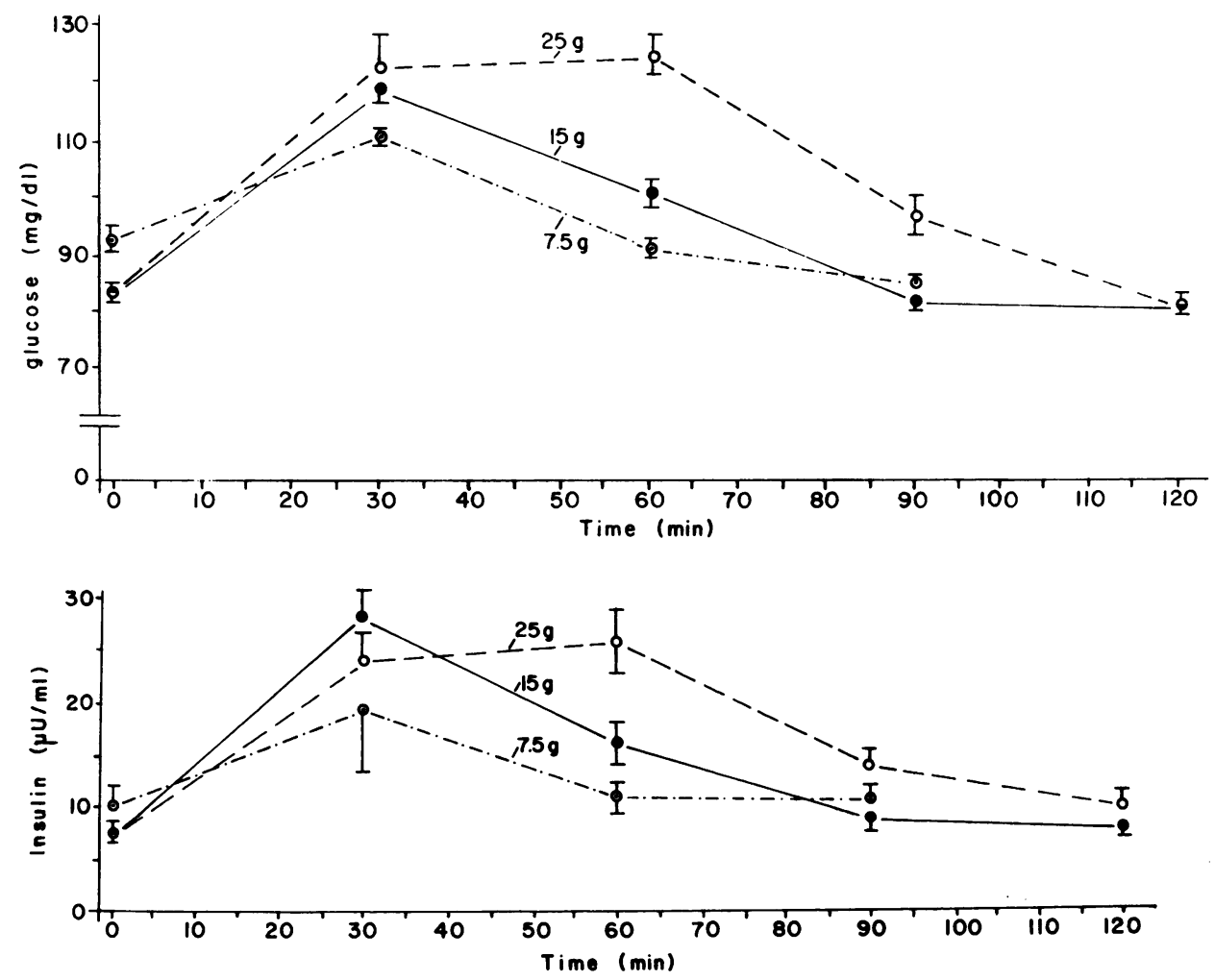

Figure 1. Glucose and insulin concentrations during 15- and 25-g oral glucose loads. Glucose and insulin concentrations had returned to stable baseline concentrations prior to initiating the $120-\mathrm{min} 20-\mathrm{mU} / \mathrm{m}^{2} \cdot \mathrm{min}$ euglycemic insulin infusions. 
Table III. Results of 120-min Euglycemic Insulin Infusions $\left(20 \mathrm{mU} / \mathrm{m}^{2} \cdot \mathrm{min}\right)$ Performed on Two Consecutive Days in Subjects Receiving 7.5, 15, or $25 \mathrm{~g}$ of Glucose on One of the Days

\begin{tabular}{|c|c|c|c|c|c|c|c|}
\hline $\begin{array}{l}\text { Study } \\
\text { performed }\end{array}$ & $\begin{array}{l}\text { Mean arterialized } \\
\text { glucose concentration } \\
\text { during infusion* }\end{array}$ & CV & $\begin{array}{l}\text { Mean serum } \\
\text { insulin level } \\
\text { during infusion } ¥ \S\end{array}$ & $\begin{array}{l}\text { Glucose infusion } \\
\text { rate } \mathrm{GIR}_{20-1205}\end{array}$ & $\begin{array}{l}\text { Percent increase of } \\
\text { GIR } 20-120 \text { from } \\
\text { basal day }\end{array}$ & $\begin{array}{l}\text { Glucose infusion } \\
\text { rate GIR } \text { sa-120 }^{-12}\end{array}$ & $\begin{array}{l}\text { Percent increase of } \\
\text { GIRea-120 from } \\
\text { basal day }\end{array}$ \\
\hline & $m g / d l$ & $\%$ & $\mu U / m l$ & $m g / k g \cdot \min$ & $\%$ & $\mathrm{mg} / \mathrm{kg} \cdot \min$ & $\%$ \\
\hline \multicolumn{8}{|c|}{ Without oral } \\
\hline glucose & 90 & 3 & $36.2 \pm 1$ & $4.36 \pm .5$ & & $4.67 \pm .4$ & \\
\hline \multicolumn{8}{|l|}{7.5 -g oral } \\
\hline glucose & 87 & 3 & $35.7 \pm 2$ & $4.58 \pm .1$ & $6.5 \pm 13$ & $5.14 \pm .2$ & $11.2 \pm 15$ \\
\hline $\begin{array}{c}\text { Without or } \\
\text { glucose }\end{array}$ & 83 & \multicolumn{3}{|c|}{ Without oral } & & & \\
\hline \multicolumn{8}{|l|}{$15-\mathrm{g}$ oral } \\
\hline $\begin{array}{l}\text { Without ora } \\
\text { glucose }\end{array}$ & 81 & 4 & $36.9 \pm 3$ & $4.68 \pm .3$ & $44.0 \pm 0^{\circ}$ & $5.39 \pm .3$ & $41.0 \pm 811$ \\
\hline \multicolumn{8}{|l|}{ 25-g oral } \\
\hline glucose & 79 & 4 & $34.8 \pm 3$ & $6.60 \pm .3$ & $46.8 \pm 9 \pi$ & $7.28 \pm .4$ & $38.2 \pm 7 \pi$ \\
\hline
\end{tabular}

$\mathrm{CV}$, coefficient of variation.

* The glucose of each subject represents the mean of 24 values during the insulin infusion. The mean glucose in this table represents the mean of those individual mean values. $\ddagger$ The insulin of each subject represents the mean of six values during the insulin infusion. The mean insulin in this table represents the mean of those individual mean values. § Values represent the mean \pm SEM. " $P<0.0002$. I $P<0.0001$.

At the conclusion of the euglycemic insulin infusions the administration of insulin was stopped, but the variable-rate glucose infusion was continued until it was no longer necessary to
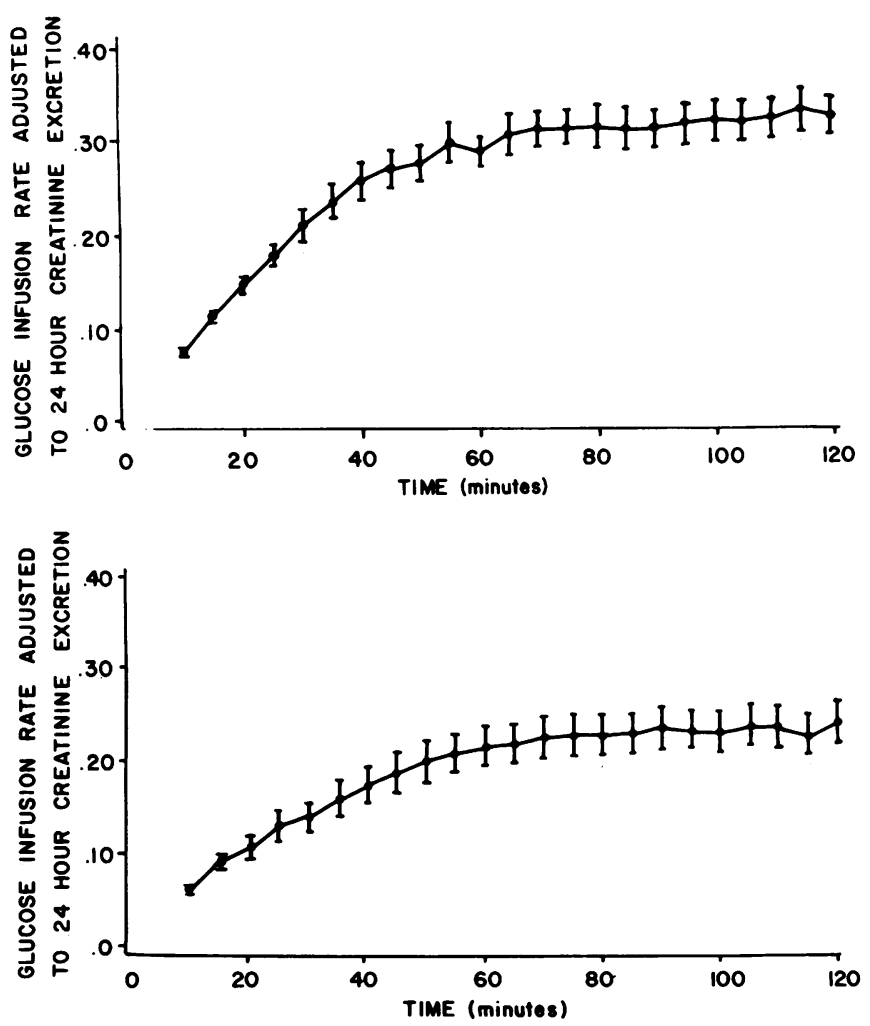

Figure 2. Glucose infusion rates (GIR) are shown as mean \pm standard error of the mean for the 120-min euglycemic insulin infusions (20 $\mathrm{mU} / \mathrm{m}^{2} \cdot \mathrm{min}$ ) given with and without prior ingestion of either $15 \mathrm{~g}$ (left) or $25 \mathrm{~g}$ (right) of glucose. The bottom panels present GIR during studies without prior glucose administration. The top panels give results during insulin infusions after glucose ingestion. 16 subjects received studies before and after a $15-\mathrm{g}$ oral glucose load and 13 subjects maintain the baseline concentration of blood glucose. Such glucose infusions were needed for 30-60 min after discontinuing the administration of insulin.
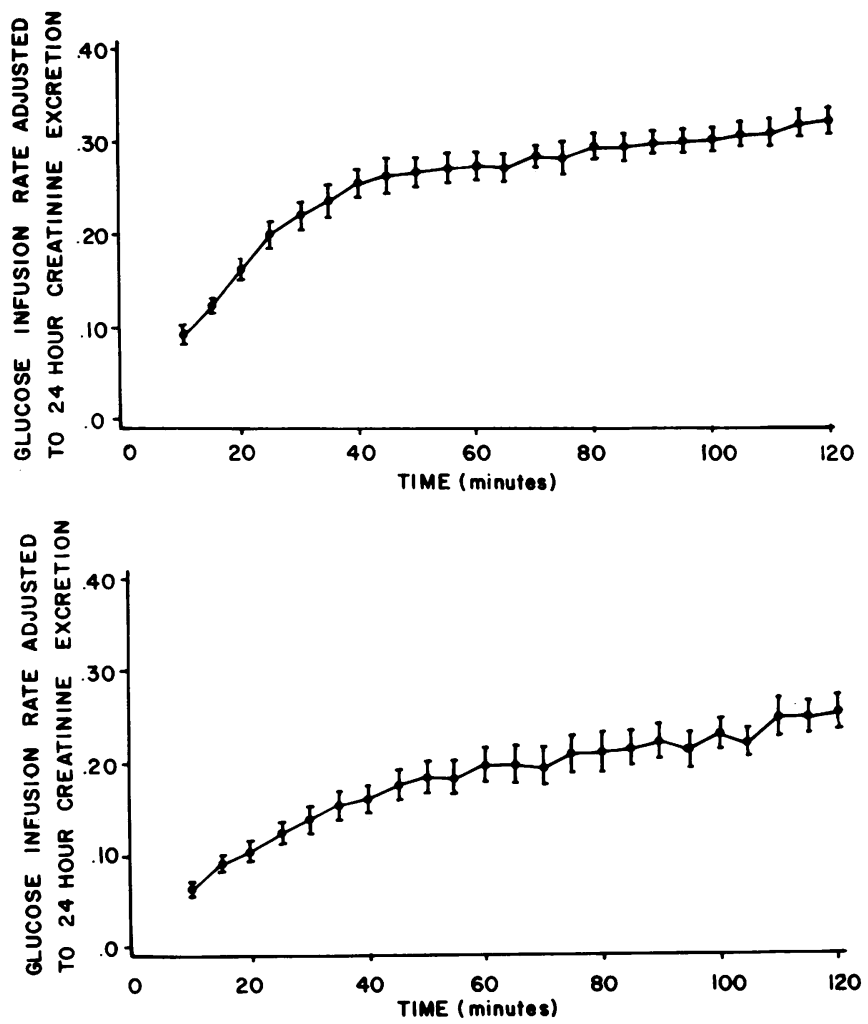

before and after a dose of $25 \mathrm{~g}$. All the GIR were adjusted to the 24-h urinary creatinine excretion rate to allow comparison of GIR values at a common unit of lean body mass. The calculation of GIR adjusted to creatinine excretion was made as follows: GIR creatinine adjusted $=$ $\mathrm{GIR}_{20-120 \text { min }} \times$ wt/24-h creatinine excretion rate, where $\mathrm{GIR}_{20-120 \text { min }}$ is expressed in milligrams per kilogram of body weight per minute, weight (wt) in kilograms, and creatinine excretion in milligrams. 
Table IV. Counterregulatory Hormones at the Start and After 120 min of Euglycemic Insulin Infusions $\left(20 \mathrm{mU} / \mathrm{m}^{2} \cdot \mathrm{min}\right)$ before and after 15- and 25-g Oral Glucose Loads

\begin{tabular}{|c|c|c|c|c|c|c|c|c|c|c|}
\hline & \multicolumn{2}{|l|}{ Epinephrine } & \multicolumn{2}{|l|}{ Norepinephrine } & \multicolumn{2}{|l|}{ Cortisol } & \multicolumn{2}{|l|}{ Glucagon } & \multicolumn{2}{|c|}{ Growth hormone } \\
\hline & 0 & 120 & 0 & 120 & 0 & 120 & 0 & 120 & 0 & 120 \\
\hline & $p g / m l$ & & $p g / m l$ & & $\mu g / d l$ & & $p g / m l$ & & $n g / m l$ & \\
\hline Basal & $32.4 \pm 7.7$ & $33.3 \pm 6.6$ & $220.5 \pm 4.5$ & $222.7 \pm 30.5$ & $7.1 \pm 1.2$ & $7.1 \pm .8$ & $56.7 \pm 2.8$ & $43.7 \pm 4.3$ & $5.50 \pm 2.18$ & $3.36 \pm 1.10$ \\
\hline $\begin{array}{l}\text { Post } 15 \mathrm{~g} \text { of } \\
\text { glucose }\end{array}$ & $32.0 \pm 3.6$ & $33.8 \pm 6.9$ & $181.0 \pm 37.5$ & $158.0 \pm 28.0$ & $8.1 \pm 1.2$ & $6.3 \pm .5$ & $54.7 \pm 1.7$ & $42.7 \pm 3.0$ & $5.83 \pm 3.41$ & $2.44 \pm 1.14$ \\
\hline Basal & $41.8 \pm 3.7$ & $43.8 \pm 6.2$ & $272.7 \pm 33.8$ & $271.0 \pm 39.0$ & $8.1 \pm 1.1$ & $6.7 \pm .9$ & $57.5 \pm 8.5$ & $47.3 \pm 3.3$ & $4.02 \pm 1.68$ & $1.49 \pm .66$ \\
\hline $\begin{array}{l}\text { Post } 25 \mathrm{~g} \text { of } \\
\text { glucose }\end{array}$ & $43.4 \pm 4.2$ & $28.5 \pm 4.9$ & $287.3 \pm 9.3$ & $252.7 \pm 35.7$ & $8.3 \pm 1.3$ & $6.8 \pm .5$ & $58.5 \pm 5.5$ & $44.0 \pm 2.3$ & $4.27 \pm 1.58$ & $1.12 \pm .12$ \\
\hline
\end{tabular}

All values represent the mean \pm SEM.

The 7.5-g dose of glucose failed to produce the degree of enhancement in the action of insulin seen after the 25- and 15$\mathrm{g}$ doses. No consistent increase in insulin action occurred and only a limited number of $7.5-\mathrm{g}$ studies were performed. Attempts were made to use a $100-\mathrm{g}$ oral glucose load. However, the long time period required for blood glucose to return to baseline $(268 \pm 10 \mathrm{~min})$ and the generation of a hypoglycemic response in two of the six subjects studied led us to abandon the use of artificially large glucose loads.

To determine whether the $25-\mathrm{g}$ and $15-\mathrm{g}$ oral glucose loads produced a significant change in counterregulatory hormones during the insulin infusions given after the carbohydrate ingestion, epinephrine, norepinephrine, dopamine, cortisol, glucagon, and growth hormone levels were measured at the start and at the completion of the 120-min euglycemic insulin infusion in six subjects. All measurements were performed at comparable times during the two euglycemic insulin infusions on the $2 \mathrm{~d}$ of study (i.e., with and without prior glucose administration). Table IV summarizes the data for each of these hormones except dopamine, which did not show any measurable change in its concentration in any of the subjects. The other hormones had minor changes in concentration during the insulin infusion, but no significantly different patterns of change for the different hormones appeared after the 25- and 15-g glucose loads when compared to the basal day insulin infusions.

Oral mannitol and oral saline control studies. 25- and 15-g oral mannitol loads were given to four subjects in a volume identical to that used in the 25- and 15-g oral glucose experiments to determine whether the increase in insulin action seen after oral glucose was due to an intestinal stimulus unrelated to an elevation of blood glucose or insulin. Two additional subjects received oral saline in a volume identical to that used in the oral glucose studies. In all of these studies, glucose and insulin levels remained at their initial basal values when measured at $30-\mathrm{min}$ intervals over a 2 -h period after mannitol or saline ingestion. Comparison of the results obtained during the $120-\mathrm{min} 20 \mathrm{mU} /$ $\mathrm{m}^{2} \cdot \min$ euglycemic insulin infusions performed after oral mannitol or oral saline to the results obtained during the basal study (no oral intake), failed to show evidence of enhancement in the rate of whole-body glucose disposal (Table V).

Studies to simulate the release of insulin produced by oral glucose. In order to determine whether a transient elevation in

Table V. Results of 120-min Euglycemic Insulin Infusions $\left(20 \mathrm{mU} / \mathrm{m}^{2} \cdot\right.$ min) Performed on Two Consecutive Days in Subjects Receiving Oral Mannitol or Saline on One of the Two Days

\begin{tabular}{|c|c|c|c|c|c|c|c|}
\hline Study performed & $\begin{array}{l}\text { Mean arterialized } \\
\text { glucose concentration } \\
\text { during infusion* }\end{array}$ & CV & $\begin{array}{l}\text { Mean serum } \\
\text { insulin level } \\
\text { during infusion‡ }\end{array}$ & $\begin{array}{l}\text { Glucose infusion } \\
\text { rateł GIR } \text { Gl-120 }^{2}\end{array}$ & $\begin{array}{l}\text { Percent increase } \\
\text { of GIR } 20-120 \\
\text { from basal day‡ }\end{array}$ & $\begin{array}{l}\text { Glucose infusion } \\
\text { rateł GIR } \text { G0-120 }^{2}\end{array}$ & $\begin{array}{l}\text { Percent increase of } \\
\text { GIR } \\
\text { basal day from }\end{array}$ \\
\hline & $m g / d l$ & $\%$ & $U / m l$ & $m g / k g \cdot m i n$ & $\%$ & $\mathrm{mg} / \mathrm{kg} \cdot \min$ & $\%$ \\
\hline Without oral & & & & & & & \\
\hline mannitol & 83 & 4 & $34.9 \pm 1$ & $4.43 \pm .7$ & & $5.38 \pm .6$ & \\
\hline $15 \mathrm{~g}$ oral & & & & & & & \\
\hline mannitol & 78 & 4 & $32.0 \pm 1$ & $4.90 \pm 1.2$ & $8.9 \pm 10$ & $5.67 \pm 1.2$ & $4.1 \pm 10$ \\
\hline $\begin{array}{c}\text { Without oral } \\
\text { mannitol }\end{array}$ & 82 & 4 & $33.2 \pm 1$ & $4.61 \pm 1.1$ & & $5.30 \pm 1.1$ & \\
\hline $25 \mathrm{~g}$ oral & & & & & & & \\
\hline mannitol & 81 & 4 & $31.5 \pm 2$ & $3.43 \pm .7$ & $-24.8 \pm 3$ & $3.96 \pm .7$ & $-24.8 \pm 2$ \\
\hline $\begin{array}{l}\text { Without oral } \\
\text { saline }\end{array}$ & 87 & 5 & $38.8 \pm 4$ & $3.77 \pm .5$ & & $4.33 \pm .9$ & \\
\hline $\begin{array}{l}200 \mathrm{ml} \text { normal } \\
\text { saline }\end{array}$ & 81 & 5 & $34.4 \pm 5$ & $3.03 \pm .6$ & $-20.3 \pm 5$ & $3.38 \pm .7$ & $-22.0 \pm 1$ \\
\hline
\end{tabular}

$\mathrm{CV}$, coefficient of variation.

* See the footnotes to Table III for methods of calculating mean glucose and mean insulin values. $¥$ Values represent the mean \pm SEM. 

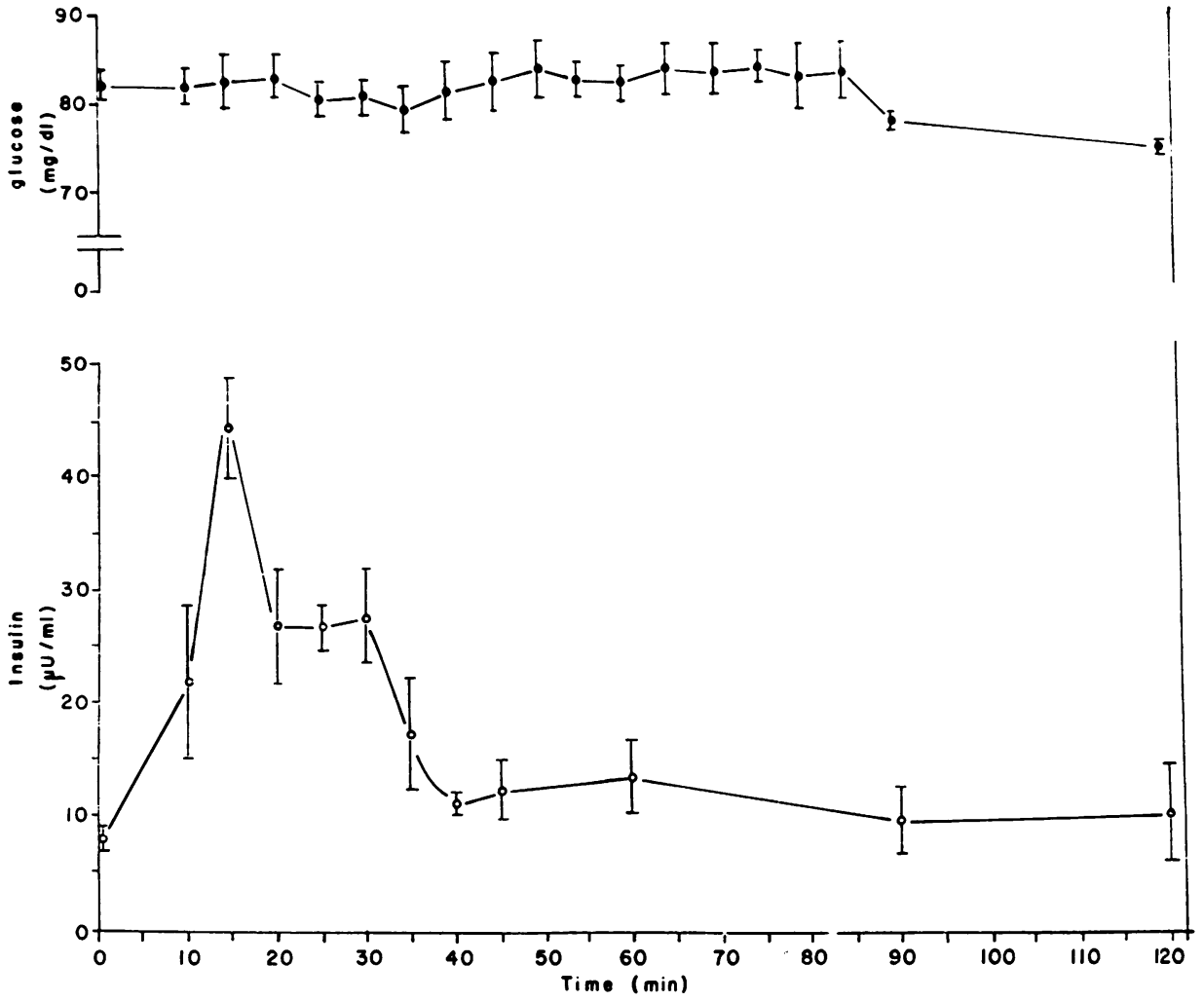

Figure 3. Glucose and insulin concentrations during the insulin simulation studies. Insulin was infused in an incremental-decremental manner to mimic the insulin concentrations observed during the 15- and 25-g oral glucose loads. Glucose was maintained at its baseline level with a variable rate glucose infusion. When no further glucose infusion was required to maintain euglycemia, an additional 30-min interval was given prior to initiating the 120 -min $20 \mathrm{mU} /$ $\mathrm{m}^{2} \cdot \min$ euglycemic insulin infusions. the systemic concentration of insulin, similar to the rise seen after 25 or $15 \mathrm{~g}$ of oral glucose, was able to produce a rapid enhancement in insulin action, nine subjects received the following insulin simulation studies. Insulin was infused intravenously at a variable rate over a $30-60 \mathrm{~min}$ period. This infusion attempted to mimic the profile of insulin levels seen in arterialized serum obtained after the 25- and 15-g doses of oral glucose (Fig. 3). During these studies glucose was infused to maintain blood glucose concentrations at their basal level. The amount of glucose infused to maintain euglycemia was $12.25 \pm 3.16 \mathrm{~g}$ (mean \pm SEM). The results of the $120-\mathrm{min} 20-\mathrm{mU} / \mathrm{m}^{2} \cdot \mathrm{min}$ euglycemic insulin infusion performed after the insulin stimulation study were compared to those obtained on the baseline study. Fig. 4 presents the GIR $_{20-120}$ values which show a $34 \%$ increase in the rate of glucose infusion after insulin simulation. The GIR $_{80-120}$ value showed a $30 \%$ increase over basal. This rapid enhancement in insulin action occurred without a change in the concentration of glucose in arterialized blood and without direct activation of physiologic changes related to the oral intake of liquid.

Endogenous glucose production during the euglycemic insulin infusions. To determine whether there was a change in the rate of hepatic glucose production during the 120-min euglycemic insulin infusion after the 25- and 15-g oral glucose doses, four subjects received $\left[3-{ }^{3} \mathrm{H}\right]$ glucose infusions during the 15 - and $25-$ $\mathrm{g}$ oral glucose studies to assess hepatic glucose output. Table VI summarizes the results of these investigations. No significant difference in the rate of hepatic glucose production during the insulin infusion after oral glucose was seen compared to the hepatic glucose output during the basal study in which no oral glucose was given. Both of these euglycemic insulin infusions produced almost complete suppression of hepatic glucose production as estimated by the $\left[3-{ }^{3} \mathrm{H}\right]$ glucose infusion technique.
To evaluate whether the rate of glucose appearance remained elevated for a prolonged period of time (a few hours) after ingestion of these small doses of oral glucose, five additional subjects underwent tritiated glucose infusions for $3 \mathrm{~h}$ before and for $4 \mathrm{~h}$

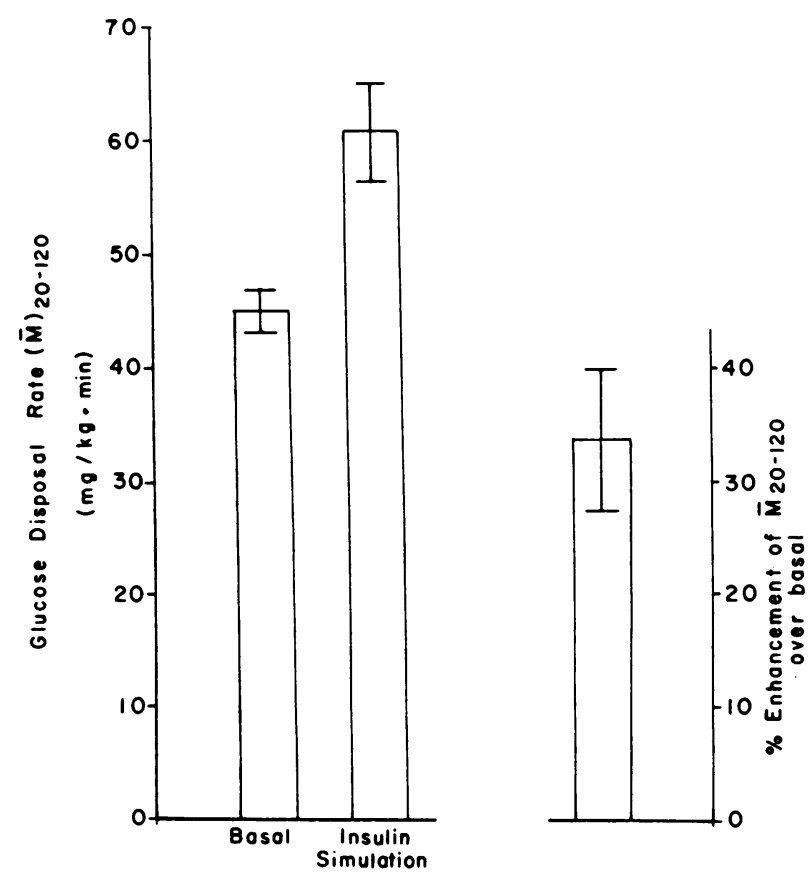

Figure 4. The glucose infusion rate (GIR) during 20-120 min of the euglycemic insulin infusion $\left(20 \mathrm{mU} / \mathrm{m}^{2} \cdot \mathrm{min}\right)$ which followed the insulin simulation (Fig. 3 ) is shown along with the percent increase in GIR $_{20-120}$ over that observed during the euglycemic insulin infusion without the prior transient elevation of circulating insulin level. 
Table VI. Endogenous Glucose Production at Baseline and during the 90-120-min Interval of $20 \mathrm{mU} / \mathrm{m}^{2} \cdot \min$ Euglycemic Insulin Infusions

\begin{tabular}{|c|c|c|c|c|c|}
\hline & Basal HGO* & $R_{0} 90-120 \%$ & $\mathrm{GIR}_{90-120 \S}$ & $\mathrm{HGO}_{90-120^{*}}$ & \% Suppression" \\
\hline & $m g / k g \cdot \min$ & $m g / k g \cdot \min$ & $\mathrm{mg} / \mathrm{kg} \cdot \min$ & $\mathrm{mg} / \mathrm{kg} \cdot \min$ & \\
\hline Basal $(n=9)$ & $2.32 \pm 0.10$ & $5.35 \pm 0.44$ & $5.05 \pm 0.48$ & $0.30 \pm 0.12$ & $86.5 \pm 5.35$ \\
\hline Post-glucose $(n=4) \pi$ & - & $8.66 \pm 0.45$ & $8.47 \pm 0.40$ & $0.19 \pm 0.05$ & $92.7 \pm 1.55$ \\
\hline
\end{tabular}

* HGO, hepatic glucose output. $\ddagger R_{\mathrm{a}}$, glucose appearance rate. $\S \mathrm{GIR}_{90-120}$, glucose infusion rate during the period $90-120$ min of the euglycemic insulin infusion. "\% suppression, percent suppression of hepatic glucose output. $\Pi(n=4)$ A subgroup of normals had measurements of HGO during euglycemic insulin infusions given with and without prior glucose ingestion.

after ingestions at a $15-\mathrm{g}$ glucose load. The specific activity of tracer glucose returned to baseline $\sim 90-100$ min after the oral glucose load and the rate of hepatic glucose produced remained at basal levels after that time. These data indicate that there was no persisting suppression of hepatic glucose production during the euglycemic insulin infusion given on the day with prior glucose administration.

\section{Discussion}

The present investigations show that $25-$ and $15-\mathrm{g}$ doses of oral glucose produce a rapid increase in whole body insulin sensitivity to a subsequent infusion of insulin. This rapid enhancement of insulin action occurred within the first $40 \mathrm{~min}$ of the $20-\mathrm{mU} /$ $\mathrm{m}^{2} \cdot \mathrm{min}$ euglycemic insulin infusion after the oral glucose challenge. The slope of the glucose disposal rate curves from the 10to 30-min points after the start of the insulin infusion was increased by one and a half times $(P<0.01)$ with oral glucose in comparison to the slope in studies not preceded by an oral glucose load (Fig. 2). The rapid increase in insulin action produced by 25- and 15-g glucose ingestion persisted throughout the 120-min period of insulin infusion.

This effect of oral glucose could not be explained by changes in the concentrations of counterregulatory hormones or in the degree of suppression of hepatic glucose production, because they were not altered. It could be hypothesized that differential changes in the rate of hepatic glucose production could account for the rapid increase in whole-body insulin sensitivity seen after administration of 15 - and $25-\mathrm{g}$ oral glucose loads. However, it would be necessary to propose that hepatic glucose production was fully suppressed during the euglycemic insulin infusion given after the oral glucose loads and that it was minimally suppressed during the euglycemic insulin infusion without prior glucose. Even with these circumstances which are refuted by the results of the tritiated glucose studies in this report, one could account for at most an enhancement of glucose infusion rate of $2 \mathrm{mg} /$ $\mathrm{kg} \cdot \mathrm{min}$. The average increase above the baseline studies in GIR after glucose ingestion was $3-4 \mathrm{mg} / \mathrm{kg} \cdot \mathrm{min}$. This would mean that even with differential effects on the rate of hepatic glucose production, there would still be $1-2 \mathrm{mg} / \mathrm{kg} \cdot \mathrm{min}$ of glucose infusion that could not be explained by an isolated effect of the liver. The present data indicate that there is no significant role for the liver in mediating the rapid increase in insulin action.

The possibility that insulin directly mediates the enhancement in insulin action after the 15- and 25-g oral glucose loads deserves serious consideration. One might wonder if intact insulin is still occupying a significant number of insulin receptors $2 \mathrm{~h}$ after these glucose loads and producing an ongoing stimulation of muscle glucose uptake. Previous investigations in this laboratory (29) and elsewhere (30-32) using the forearm intraarterial insulin infusion technique have shown that maintaining an elevation of arterial insulin concentration between 150 and $500 \mu \mathrm{U} / \mathrm{ml}$ for $25-35 \mathrm{~min}$ will produce a tenfold increase in muscle glucose uptake by $35-45 \mathrm{~min}$. This glucose uptake falls back toward normal over a 2 -h period, but can remain elevated by threefold over basal 90-120 min after the start of the 25-35min infusion of insulin $(31,32)$. However, this enduring effect of insulin appears to depend in large measure upon the absolute elevation in steady-state insulin concentration achieved during these forearm studies. In studies in this laboratory in which forearm venous insulin levels remained in the range of 30-80 $\mu \mathrm{U} /$ $\mathrm{m}$ l during intraarterial forearm insulin infusion, the stimulatory effect on muscle glucose uptake had disappeared by $85 \mathrm{~min}$ after the start of insulin infusion. In more extensive studies of forearm response to insulin by others using a lower dose insulin infusion $(10 \mu \mathrm{U} / \mathrm{kg} \cdot \mathrm{ml})$, designed to produce deep venous elevations of insulin to 20 to $40 \mu \mathrm{U} / \mathrm{ml}(32,33)$, a significant stimulation in muscle glucose uptake occurred only transiently at $\mathbf{4 5} \mathrm{min}$ after the start of insulin infusion in one study (32) and failed to occur in the other investigation (33). The peak systemic elevation in the concentration of insulin observed in the subjects in the present study after the 15- and 25-g oral glucose loads were generally lower than the steady-state elevation maintained for 25-35 min in the forearm studies just noted above $(32,33)$. A recent study of degradation of intact tracer insulin by forearm tissues demonstrated that $1 \mathrm{~h}$ after a 60 -min high physiologic infusion of insulin into the brachial artery, that all intact tracer insulin had undergone degradation (34). Based upon these forearm studies, it seems unlikely that a continuing action caused by elevated levels of intact insulin can account for the enhancement seen in insulin sensitivity $2 \mathrm{~h}$ after glucose ingestion. Further support for this interpretation comes from the fact that, after discontinuation of the $120-\mathrm{min} 20-\mathrm{mU} / \mathrm{m}^{2} \cdot \mathrm{min}$ euglycemic insulin infusions in the present study, arterialized glucose concentrations were maintained at baseline with a decremental glucose infusion for 30-60 min. No glucose infusion was required to maintain euglycemia after that $30-60$-min interval.

The regulation of the action of insulin on its peripheral target tissues is complex. Although further studies may discover multiple physiologic mechanisms for the rapid enhancement of insulin action that depends on the inciting cause (oral glucose, exercise, etc.), the possibility exists that gastrointestinal factors help mediate the response after glucose ingestion. Gastric inhibitory polypeptide (GIP) is an attractive possibility since it causes insulinlike effects in fat cells (35), and has been considered by some investigators to enhance target tissue sensitivity (36).

Previous studies of the human forearm have shown that intrabrachial arterial infusions of a mixture of growth hormone 
plus insulin leads to a decrease in the action of insulin compared to that seen when insulin is infused alone (30). It can be reasoned that the converse may be true: that a fall in the normal plasma concentration of growth hormone may lead to a transient increase in the action of a given concentration of insulin on its target tissues. More recent studies have discussed a possible role for a decrease in plasma growth hormone as a mechanism for mediating an increase in insulin action (37). However, in the present studies we have not observed a significant difference in the degree of fall in plasma growth hormone levels during those euglycemic insulin infusions that followed glucose ingestion compared to those infusion studies that did not (Table IV). These findings argue against changes in growth hormone as an explanation for the rapid increase in the action of insulin described in the present report.

A quite good candidate for mediating the rapid enhancement in insulin sensitivity is insulin itself. Past investigations of normal humans have shown that infusion of insulin for $8 \mathrm{~h}$ at sequential rates ( $2 \mathrm{~h}$ at each step) from 0.2 to $5.0 \mathrm{mU} / \mathrm{kg} \cdot \mathrm{min}$ provides a more rapid achievement of steady-state glucose infusion rates than those during separate $2-\mathrm{h}$ insulin infusions at these rates (38). This effect of a prior dose of insulin on target tissues may be involved in the mechanism that accounts for the rapid increase in whole body sensitivity to insulin seen in the present studies. As the stimulation studies in this report show, simply raising insulin levels for 30-60 min made the in vivo response to subsequent insulin more efficient. Whether this is a direct priming effect of insulin on target tissues like muscle or whether the hormone causes the release of another factor that in turn acts on muscle is not known. It is possible that more than one mechanism is involved. For example, the insulin simulation studies, which overall resulted in somewhat higher insulin levels than those found with the 15- and 25-g oral glucose loads, failed to produce as good an effect as the oral sugar. Thus gut hormones or other factors may contribute directly to help mediate the increase in insulin sensitivity.

It is important to note that the increase in insulin action mediated by oral glucose was measured using a physiologic rather than a supraphysiologic insulin concentration. Pilot studies were performed using high physiologic rates of insulin infusion, 30 and $40 \mathrm{mU} / \mathrm{m}^{2} \cdot \mathrm{min}$, and these studies showed less of an enhancement in whole body glucose disposal after 15 and $25 \mathrm{~g}$ of glucose than found with the $20 \mathrm{mU} / \mathrm{m}^{2} \cdot \mathrm{min}$ insulin infusion rate. The present investigation did not attempt to determine whether oral glucose produced a rapid increase in maximum responsiveness to insulin, but the pilot data suggest that the primary effect on insulin action is to increase insulin sensitivity of target tissues.

The physiologic significance of the rapid enhancement in insulin action seen in the present investigations remains to be established, but it may have considerable importance in defining the pathophysiology for certain insulin-resistant states. Recent studies in this laboratory have demonstrated that insulin-resistant patients with myotonic dystrophy fail to develop any significant enhancement in their rate of whole body glucose disposal as determined by euglycemic insulin infusions given after either 25- or 15-g doses of oral glucose (39). It seems reasonable to ask if insulin resistance owing to obesity or diabetes mellitus may also involve a compromise in this aspect of the regulation of insulin action. As a clearer understanding of the mechanisms responsible for the acute regulation of insulin action evolves, it may become possible to improve this response, if needed. For example, one recent report has shown an improvement in insulin action in the whole body within several hours after phenobarbital administration (40). Thus, subsequent research in this area may help establish the means to ameliorate insulin resistance.

\section{Acknowledgments}

Barbara Evelyn Herr and Timothy Downs provided major technical assistance in these studies. We thank Kristin Bass, Terry Chadwick, David J. Goldblatt, Jennifer Griggs, Sandra Kauffman, and Edward Rozmiarek for technical aid in these investigations, and the nurses, dietary, and technical staff of the University of Rochester Clinical Research Center for valuable help.

This research was supported in part by research grants from the Muscular Dystrophy Association, the Waasdorp Foundation, and U. S. Public Health Service grant RR-00044 from the Division of Research Resources of the National Institutes of Health of Arthritis, Metabolism, and Digestive Diseases (AM-32884).

Dr. Kingston's research was supported by a Biomedical Research Support Grant (National Institutes of Health). This research was carried out in part during Dr. Kingston's tenure of a Postdoctoral Fellowship from the Muscular Dystrophy Association.

\section{References}

1. Hamman, L., and I. I. Hirschman. 1919. Studies on blood sugar. IV. Effects upon the blood sugar of repeated ingestion of glucose. Bull. Johns Hopkins Hosp. 30:306-308.

2. Staub, H. 1921. Untersuchungen über den Zuckerstoffwechsel des Menschen. I Mitteilung. Z. Klin. Med. 91:44-60.

3. Traugott, K. 1922. Über das Verhalten des Blutzuckerspiegels bei wiederholter und verschiedener Art enteraier Zucherzufuhr und dessen. Bedeutung für die Leberfunction. Klin. Wochenschr. 1:892-894.

4. Exton, W. G., and A. R. Rose. 1934. A one-hour two dose glucose tolerance test based on Allen's paradoxical law. Am. J. Clin. Pathol. 4: 381-399.

5. Somersalo, O. 1950. Staub effect on children. Studies of the blood sugar regulation by means of double and triple glucose tolerance tests. Acta Paediatr. 78-79:1-126.

6. Abraira, C., and A. M. Lawrence. 1978. The Staub-Traugott phenomenon. III. Effects of starvation. Am. J. Clin. Nutr. 31:213-221.

7. Bar, R., L. C. Harrison, M. Muggeo, P. Gorden, C. R. Kahn, and J. Roth. 1979. Regulation of insulin receptors in normal and abnormal physiology in humans. Adv. Intern. Med. 24:23-68.

8. Moxley, R. T. III, J. N. Livingston, D. H. Lockwood, R. C. Griggs, and R. L. Hill. 1981. Abnormal regulation of monocyte insulin-binding affinity after glucose ingestion in patients with myotonic dystrophy. Proc. Natl. Acad. Sci. USA. 78:2567-2571.

9. Muggeo, M., R. S. Bahr, and J. Roth. 1977. Change in affinity of insulin receptors following oral glucose in normal adults. J. Clin. Endocrinol. Metab. 44:1206-1209.

10. Arner, P., J. Bolinder, and J. Ostman. 1983. Marked increase in insulin sensitivity of human fat cells one hour after glucose ingestion. $J$. Clin. Invest. 71:709-714.

11. Livingston, J. N., and R. T. Moxley III. 1982. Glucose ingestion mediates a rapid increase in the insulin responsiveness of rat adipocytes. Endocrinology. 111:1749-1751.

12. Defronzo, R. A., J. D. Tobin, and R. Andres. 1979. Glucose clamp technique: a method for quantifying insulin secretion and resistance. Am. J. Physiol. 237:E214-223.

13. Defronzo, R. A., E. Jacot, E. Jequier, E. Maeder, J. Wahren, and J. P. Felber. 1981. The effect of insulin on the disposal of intravenous glucose. Results from indirect calorimetry and hepatic femoral venous catheterization. Diabetes. 30:1000-1007.

14. McGuire, E. A. H., H. J. Helderman, J. D. Tobin, R. Andres, and M. Berman. 1976. Effects of arterial versus venous sampling on analysis of glucose kinetics in man. J. Appl. Physiol. 41:565-573. 
15. Defronzo, R. A., V. Soman, R. S. Sherwin, R. Hendler, and P. Felig. 1978. Insulin binding to monocytes and insulin action in human obesity, starvation, and refeeding. J. Clin. Invest. 62:204-213.

16. Steel, R. 1959. Influences of glucose loading and of injected insulin on hepatic glucose output. Ann. N. Y. Acad. Sci. 82:420-430.

17. Cowan, J. S., and C. Hetenyi. 1971. Glucoregulatory responses in normal and diabetic dogs recorded by a new tracer method. Metab. Clin. Exp. 20:360-372.

18. Radzuik, J., K. H. Norwich, and M. Vranic. 1974. Measurement and validity of nonsteady turnover rates with applications to the insulin and glucose systems. Fed. Proc. 33:1855-1864.

19. Snedecor, W. G. 1967. Statistical methods applied to experiments in agriculture and biology. Iowa State University Press, lowa. 6th edition. $1-593$.

20. Faloona, G. R., and R. H. Unger. 1974. Glucagon. In Methods of Hormone Radioimmunoassay. B. M. Jaffee, and H. R. Behrman, editors. Academic Press, Inc., New York. 317-330.

21. Unger, R. H., A. M. Eisentraut, M. S. McCall, and L. L. Madison. 1961. Glucagon antibodies and an immunoassay for glucagon. J. Clin. Invest. 40:1280-1289.

22. Soeldner, J. S., and D. S. Slone. 1965. Critical variables in the radioimmunoassay of serum insulin using the double antibody technique. Diabetes. 14:771-779.

23. Morgan, C. R., and A. Lazarow. 1963. Immunoassay of insulin: two antibody system. Plasma insulin levels of normal, subdiabetic, and diabetic rats. Diabetes. 12:115-126.

24. Peuler, J. D., and G. A. Johnson. 1977. Simultaneous single isotope radioenzymatic assay of plasma-norepinephrine, epinephrine and dopamine. Life Sci. 21:625-636.

25. Passon, P. G., and J. D. Peuler. 1973. A simplified radiometric assay for plasma norepinephrine and epinephrine. Ann. Biochem. 51: 618-631.

26. Schalch, D. W., and M. L. Parker. 1964. A sensitive double antibody immunoassay for human growth hormone to plasma. Nature (Lond.). 203:1141-1142.

27. Bratusch-Marrain, P. R., W. K. Waldhausl, S. Gasic, A. Korn, and P. Nowotny. 1980. Oral glucose tolerance test: effect of different glucose loads on splanchnic carbohydrate and substrate metabolism in healthy man. Metab. Clin. Exp. 29:289-295.

28. Martin-Du Pau, R., C. Mauron, B. Glaeser, and R. J. Wortman.
1982. Effect of various oral glucose doses on plasma neutral amino acid levels. Metab. Clin. Exp. 31:937-943.

29. Moxley, R. T. III, R. C. Griggs, and D. Goldblatt. 1978. Decreased insulin sensitivity of forearm muscle in myotonic dystrophy. J. Clin. Invest. 62:857-867.

30. Zierler, K. L., and D. Rabinowitz. 1963. Roles of insulin and growth hormone, based on studies of forearm metabolism in man. Med icine (Baltimore). 42:382-402.

31. Andres, R., M. A. Baltzan, G. Cader, and K. L. Zierler. 1962. Effect of insulin on carbohydrate metabolism and on potassium in the forearm of man. J. Clin. Invest. 41:108-115.

32. Pozefsky, T., P. Felig, J. D. Tobin, J. S. Soeldner, and G. F. Cahill. 1969. Amino acid balance across tissues of the forearm in postabsorptive man. Effects of insulin at two dose levels. J. Clin. Invest. 48: 2273-2282.

33. Zierler, K. L., and D. Rabinowitz. 1964. Effect of very small concentrations of insulin on forearm metabolism. Persistence of its action on potassium and free fatty acids without its effect on glucose. J. Clin. Invest. 43:950-962.

34. Duckworth, W. C., S. E. Fineberg, R. G. Gibson, S. Knolling, and N. S. Fineberg. 1985. Degradation of porcine ${ }^{3} \mathrm{H}$-insulin by human forearm tissues. Diabetes. 34(Suppl. 1):58A. (Abstr.)

35. Dupre, J., N. Greenridge, T. J. McDonald, S. A. Ross, and D. Rubinstein. 1976. Inhibition of actions of glucagon in adipocytes by gastric inhibitory polypeptide. Metab. Clin. Exp. 25:1197-1199.

36. Gand, O. P., J. S. Soeldner, R. E. Gleason, I. G. M. Cleator, and C. Reynolds. 1979. Metabolic effects of glucose, mannose, galactose, and fructose in man. J. Clin. Endocrinol. Metab. 49:616-622.

37. Bergman, R. N., M. Ader, D. T. Finegood, and G. Pacini. 1984. Extrapancreatic effect of somatostatin infusion to increase glucose clearance. Am. J. Physiol. 247:E370-E379.

38. Rizza, R. A., L. J. Mandarino, and J. E. Gerich. 1981. Doseresponse characteristics for effects of insulin on production and utilization of glucose in man. Am. J. Physiol. 240:E630-E639.

39. Kingston, W. J., R. T. Moxley, J. N. Livingston, and R. C. Griggs. 1985. Lack of rapid enhancement of insulin action following oral glucose challenge in myotonic dystrophy. Neurology. 35(Suppl 1):166. (Abstr.)

40. Lahtela, J. T., P. Sarkka, and E. A. Sotaniemi. 1984. Phenobarbital treatment enhances insulin mediated glucose metabolism in man. Res. Commun. Chem. Pathol. and Pharmacol. 44:215-226. 